\title{
Editorial
}

\section{2 - An evolution, not a revolution}

Howard M. Liebman, Oppenheimer Wolff \& Donnelly, Brussels

Over the past year, much has appeared in the US press with regard to '1992' and the single internal European market. Nonetheless, US businesses are only now appearing to pay close attention to this development. The idea has become a 'fad' and is now often in the public eye. However, although many are now interested, the availability of hard information as opposed to speculation is still rather sparse.

Indeed, two trends appear to have manifested themselves in the United States in this regard. One is an increasing thirst for more information and knowledge concerning the concept and content of the '1992 programme'. There just does not seem to be enough information available which is really of use and assistance to US multinationals or even, perhaps more importantly, to smaller US exporters eager to break into the market. On the other hand, the second tendency seems to be a flood of misinformation, innuendo and what might even be termed 'scare' tactics.

Certainly, all of the major consulting and advisory firms are printing reams of general information and offering their monitoring services. Newly-styled EC lobbyists are also seeking to sell their wares and offering specialized information services for particular industries, causing some to write of Brussels as a new 'Gucci Gulch'. See Int'l Herald Trib., 25-26 March 1989, at 8, col. 3.

None of this is to say that the explosion of general information concerning 1992 and the European Community ('EC') in general is not useful. For perhaps far too long, many US businesses probably paid insufficient attention to what the EC was all about. On the other hand, there are two very important points worth making.

First of all, 1992 has become a catch-phrase. In this respect, it has served its role well specifically that created by Lord Cockfield (the recent EC Commissioner for Internal Market Affairs) of attracting public attention to the need for creating such an internal market and to the real efforts which are already being undertaken in that direction.

Nonetheless, as a purely factual matter, the single internal market program outlined in a 1985 EC Commission White Paper establishes 31 December 1992 as its deadline for the achievement of the goals set forth therein. Thus, everyone should really be speaking about 1993 instead of 1992. Indeed, one major, US publisher has done just that in printing a new book entitled The CCH Guide to 1993.

Perhaps ' 1992 ' is catchier. Nonetheless this writer prefers to refer to 1995 to highlight the fact that the entire program is an evolutionary one. There is nothing magical about 1992 , 1993 or 1995 . Many efforts are currently underway and much has already been achieved since 1985.

No one should expect a revolutionary change as from night to day in 1992, 1993 or 1995. Nor should businessmen necessarily feel pressured by the so-called 1992 deadline. An evolutionary process is always a 'moving target'.

As a consequence, a second point which has not perhaps received the attention which it merits is that it is not necessarily correct for all US companies to be inordinately concerned to 'jump into the fray'. Many companies have been goaded by the press and over-eager consultants into so-called 'strategic acquisitions' in order to better implant themselves in Europe prior to 1992. Their actions are based on a fear of a 'fortress Europe'.

Although certain elements of fortress-like behavior may eventually arise in certain industries - both the financial services and semi-conductors sectors having had the spotlight thrown on them in this regard - this does not mean that all industries will be similarly affected. To date, many of the most important rules which will form a part of the future single European internal market have yet to be decided upon. Many are in a proposed format, but some have yet to even be formally proposed. This is the case, for example, with the expected new package on direct corporate taxation measures. 
Thus, in the key areas of corporate organization and tax reorganization, it is indeed quite difficult for any consultant to advise his or her clients. There simply are no clear rules nor clear-cut strategies available, and blindly seeking to buttress one's position in Europe might not prove the best course of action in the long-run. More mistakes may be made in the process.

If American business would instead apply a bit of introspection, it will recognize that the single internal market which presently subsists in the United States took many decades to achieve. In certain very important respects, it was not fully attained until the 1930's when the US Supreme Court finally began upholding the Commerce Clause of the US Constitution over and above the concept of 'States' rights'. The same might be said of Europe.

1992 is a glitzy catch-phrase which has caught the public's imagination, but it should not be viewed as a hard and fast deadline for businesses to develop a European strategy. As in anything, careful planning is of prime importance, and perhaps the best that can be hoped for at this point in time is to monitor developments, seek to subtly influence them as and where necessary and develop alternative strategy scenarios. 